\title{
ACRL Continuing Education Courses at Midwinter Conference
}

The Association of College and Research Libraries will sponsor four continuing education courses at the ALA Midwinter Meeting in Washington, D.C. Advance registration by November 30,1983 , is required. A late registration fee of $\$ 10$ will be charged.

A Certificate of Completion will be awarded participants in each course. Successful completion of 10 contact hours of continuing education is equal to one Continuing Education Unit (CEU). ACRL maintains a CEU record for each participant.

To register, send in a completed registration form to Barbara Macikas, ACRL/ALA, $50 \mathrm{E}$. Huron Street, Chicago, IL 60611. Details of the courses follow:

\section{LiBRARIANS As SUPERVISORS}

CE 101 provides participants with the skills necessary to become effective supervisors in library organizations. It helps participants develop an awareness and understanding of current managerial concepts and practices. Specific objectives include: to increase self-awareness of behavior and managerial philosophy; to develop a greater appreciation of the supervisor's role and contribution to improving library performance; to gain an understanding of the skills required for effective supervision; and to examine individual approaches to supervision in response to the needs and demands of particular situations.

Instructor: Maureen Sullivan, Head of Personnel, Yale University Library.

Date: January 5, 1984, 9:00 a.m.-5:00 p.m.

Fee: ACRL members $\$ 75$, non-members $\$ 100$.

CEUs: 7 CEU.

\section{Performance Evaluation: \\ A Results-Oriented Approach}

CE 106 will introduce participants to the concept of performance evaluation based on performance goals and result-oriented evaluation. This includes explanation of different approaches and purposes for evaluation; review of how a goalsbased performance system works; practice writing performance goals; discussion of how to improve a poor evaluation system; meeting conflict in evaluation interviews; and how to make evaluation a developmental experience for the supervisors and the employee.

Instructor: Sheila Creth, Head of Personnel Services, University of Michigan Libraries.

Date: January 6, 1984, 9:00 a.m.-5:00 p.m.

Fee: ACRL members $\$ 75$, non-members $\$ 100$. CEUs: .7 CEU.

\section{Managing STUdent Workers \\ in ACADEMic Libraries}

CE 107 will help participants to develop strategies for better management of student workers. In addition to providing an opportunity for participant interaction, the course seeks to clarify the nature of the student worker's role in academic libraries and the role of the supervisor of student workers; to identify management theories appropriate to student workers; to recognize the importance of selection, training, and supervision of student workers; to identify dilemmas or problems which occur in the management of student workers; and to become familiar with the various ways in which policies and procedures can be communicated to student workers. The course is intended for librarians who have had at least one year of experience managing student workers or who have had at least one year of experience managing supervisors of student workers.

Instructors: Michael Kathman, Director of Libraries \& Media Services, St. John's University; and Jane Kathman, Assistant Professor of Economics and Business Administration, College of St. Benedict.

Date: January 6, 1984, 8:30 a.m.-5:00 p.m.

Fee: ACRL members $\$ 75$, non-members $\$ 100$. CEUs: 8 CEU.

\section{Writing the Journal Article AND Getting It Published}

CE 501 provides participants with an overview of the publishing process and helps them devise an effective strategy for publishing their work. Topics will include selection of a publishing medium, preparation of the manuscript, submission of the manuscript, and pre- and post-publication matters.

Instructor: Richard D. Johnson, Director of Libraries, State University College, Oneonta, New York (formerly editor of College \& Research Libraries and co-editor of New Horizons for Academic Librarians).

Date: January 6, 1984, 9:00 a.m.-5:00 p.m.

Fee: ACRL members $\$ 75$, non-members $\$ 100$.

CEUs: 7 CEU.

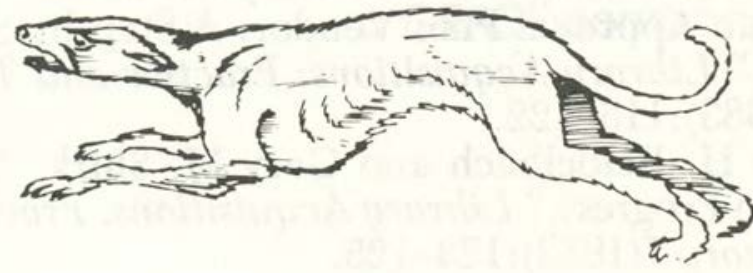

